\title{
Locus of control in maltreated children: the impact of attachment and cumulative trauma
}

\author{
Antonio Roazzi ${ }^{1 *}$, Grazia Attili ${ }^{2 \dagger}$, Lorenza Di Pentima ${ }^{2 \dagger}$ and Alessandro Toni ${ }^{2 \dagger}$
}

\begin{abstract}
Up until now research studies carried out on abused children have rarely taken in consideration the impact of maltreatment on the locus of control; furthermore results concerning the distribution of attachment internal models in this population are inconclusive. In addition, no study has ever taken in consideration the differential role of attachment and time of exposure to stress in the formation of attributive styles. This research work involved 60 maltreated children and 100 controls with the purpose of evaluating the associations between their attachment and age as for their locus of control. Internal Working Models were assessed by SAT and locus of control by the Nowicki-Strickland Scale. Results highlight mainly external locus of control and disorganized and avoidant IWMs in abused children. Furthermore, age was more predictive than attachment for locus of control. By contrast, in the control group at both age taken in consideration attachment was predictive of locus of control. Results are discussed in terms of problematic symptoms associated to maltreatment.
\end{abstract}

Keywords: Maltreatment, Child abuse, Locus of control, Attachment, Violence, Cumulative trauma, Age

\section{Background}

In the studies that have been carried out to date on maltreatment in childhood, much attention has been given to the effects of suffering physical and sexual abuse: for example, among the many effects, aggressive behavior or isolation, as studied by Lyons-Ruth and Jacobvitz (1999), attention and behavioral disorders (reported by HubbsTait et al. 1996), phobias (Beumariu \& Kerns 2010), borderline personality disorder (Fonagy 2000), anxieties (Kim et al. 2011) and depressive and dissociative symptoms (Bifulco et al. 2002; Camisasca et al. 2013; CantonCortes et al. 2015; Carlson 1998) have been highlighted. However, there has been little investigation of the impact of being a victim of maltreatment on the more basic cognitive processes, such as the ability to properly identify the causes of events. The few studies in this area show that a critical variable in determining the longterm effect of being abused or neglected is the subject's

\footnotetext{
* Correspondence: roazzi@gmail.com

${ }^{\dagger}$ Equal contributors

'Department of Psychology, Graduate Program in Cognitive Psychology, Federal University of Pernambuco, Recife, Brazil

Full list of author information is available at the end of the article
}

inability to give meaning to their experience (van der Kolk 1994).

From the articles in the literature on the association between maltreatment and styles of attribution, it can be seen that children exposed to abuse and neglect present changes in attributional processes as a result of being subjected to contexts that they are unable to control. The rejection, hostile control, lack of warm and unpredictability that characterize the styles of parents that perpetrate maltreatment, cause their children to adopt an external locus of control, i.e., a way of thinking characterized, according to the definition provided by Rotter (1966), by attributing the responsibility for what happens in their lives to destiny and to other people (Barahal et al. 1981; Ellis \& Milner 1981; Serrano et al. 1979). In other words, these few studies provide empirical evidence for the hypothesis that children suffering maltreatment-experiences defined as physical punishment not arising from their own behavior, psychological abuse, neglect or negligent care, exploitation and sexual abuse involving the deliberate use of threatened or actual physical strength and power by a person or group against a child and causing or having a good chance of causing actual or
Springer Open

(c) 2016 Roazzi et al. Open Access This article is distributed under the terms of the Creative Commons Attribution 4.0 International License (http://creativecommons.org/licenses/by/4.0/), which permits unrestricted use, distribution, and reproduction in any medium, provided you give appropriate credit to the original author(s) and the source, provide a link to the Creative Commons license, and indicate if changes were made. 
potential harm to the child's health, survival or dignity (ONU, 2006, p. 6) - have little confidence in the possibility that they can have an impact on their own experiences, especially the frustrating and unpleasant ones.

From this perspective, regarding attributional styles, Locus (place in Latin) of control is the expectation of the individual regarding how much his/her life is controlled by internal forces (personal effort, skill, etc.), or external forces (other people, luck, chance, etc.) (Phares 1976). Considering that this locus of control construct is central in this research, it is important to remember that this was initially proposed by Julian B. Rotter in 1966, in his article "Psychological Monographs", and considers that people with a predominantly internal locus of control feel more in control of their own lives and success, demanding more of themselves and focusing on what they can do on their own to deal with current problems. Individuals with a predominantly external locus of control feel that external factors have greater control over their lives, demand more from others, have greater emotional and functional dependence and are more affected by criticism and praise.

Although there is little research on these cognitive dimensions related to being a victim of maltreatment, many studies have taken into consideration the type of attachment that emerges from the experience of highly distorted and/or needy care from those who should play the role of caregiver (e. g., Lecompte \& Moss 2014; O'Connor et al. 2011; Unger 2011). The results of bad adaptation, previously highlighted (e.g., Ellis \& Milner 1981; Serrano et al. 1979), retake the point with regard to the quality of the attachment relationship in which child victims of abuse are inserted (Bacon \& Richardson 2001; McElheran et al. 2012). According to studies in this area, it appears that physically or sexually abused children, as well as neglected children, present a high probability of developing mental models of insecure attachment (Beaudoina et al. 2013; Miner et al. 2014) that are essentially configured in terms of disorganized attachment (see the revision by Cyr et al. 2010; and, specifically, Lyons-Ruth et al. 1999; Lyons-Ruth \& Jacobvitz 2008).

In other words, where there is proper care from parents, designated as ready responses to the need to feel protected and comforted, children produce mental representations, or internal working models (IWM), of themselves as individuals who can rely on others, are worthy of being loved and therefore secure (Attili 2007; Cantón \& Cortés 2008; De Wolff \& van IJzendoorn 1997; Roazzi et al. 2013). However, where care is inadequate, in terms of unpredictability in the response or in terms of distancing and the encouragement of early autonomy, a type of insecure attachment is structured, which can lead to either a tendency not to be able to regulate the emotions (as is the case of ambivalent attachment), or an inability to be able to recognize anxieties and fears (as in the case of avoidant attachment).

The result of maltreatment is dramatic: the caregiver (mother or father) not only ceases to be the figure to whom the child can turn to for protection, but also becomes the source of danger itself. As a result of this, a series of strongly contradictory, disorganized emotional and behavioral reactions, and similarly disorganized mental models are produced, which lead to the thought and behavior disorders mentioned above (Attili 2001a; Carlson et al. 1989; Main \& Solomon 1986; Main \& Solomon 1990). It is not by chance that $90 \%$ of children victims of maltreatment develop disorganized bonds (Cicchetti et al. 2006), with respect to attachment, a percentage that remains high even at an older age (Crittenden 1985; Crittenden 1992; Moss et al. 2007). From other studies a high percentage of avoidant patterns has been noted (Crittenden \& Ainsworth 1989), while the percentage of disorganization patterns during adolescence remains higher than those related to avoidance (Neufeld Bailey et al. 2007; Webster et al. 2009).

Is it possible to hypothesize a relationship between locus of control and attachment in child victims of maltreatment? If the answer is yes, in what way can this association be conceptualized? Can the hypothesis that attachment is the mediator of the association between maltreatment and locus of control be formulated? These questions are important to guide interventions in the clinical context, with the aim of reducing the devastating impact on the victims of maltreatment. However, so far no work has taken the interaction between these variables into consideration. In addition to the previously mentioned studies on the association between maltreatment and locus of control, others have separately investigated the relationship between locus of control and attachment. These studies show that insecure attachment is mainly associated with attributive styles focused on reporting events as uncontrollable factors, in which the subject, therefore, cannot intervene (Di Pentima \& Toni 2010; Gamble \& Roberts 2005; Mickelson et al. 1997; Hexel 2003; Dan et al. 2011).

An important variable that has not been properly taken into account in the literature regarding the relationship between locus of control and maltreatment, and between the latter and attachment, is the impact on these associations and intersections that can result from being exposed to violence and neglect by the parents for longer or shorter periods; that is, it has never been investigated to what extent the experiences of maltreatment suffered over time can be configured as a cumulative trauma which can affect the attachment working models, the attributional processes and their intersection.

Being the victim of maltreatment by one of the parents is a highly traumatic event, as the child, completely 
dependent on the parents, will experience the fact of being beaten, abused or neglected in a condition of painful impotence, which is the hallmark of every trauma; however, abuse repeated over time can be seen as cumulative trauma that is likely to induce disorganized reactions, though disorders and more severe behavior compared to a single isolated event of abuse: the child is in the paradoxical situation, generating an irresolvable fear of receiving ongoing physical and psychological injury from people that should provide support and protection. These prolonged experiences can lead to severe psychopathological disorders in adulthood, both as a result of these disorganized mental models, which, as previously mentioned, have been found to be correlated with maltreatment, as well as their impact on the processes of development of the information relative to the causes of events.

In other words, until now, there has been no investigation regarding whether the relationship between maltreatment, attachment and locus of control can vary as a function of different age groups it is the case of older children who have suffered maltreatment since a young age. In fact, the role of age has only been investigated with respect to the locus of control and using nonclinical samples.

The results of these studies show that, with advancing age, the locus of control changes from external to internal (LaMontagne 1984, 1987; Nowicki \& Duke 1983) and that the perception of greater control over events stems from the fact that more sophisticated cognitive skills are gained with age (Lefcourt 1982). This lead to the question: what happens to child victims of maltreatment? Moreover, which of the two factors is the one capable of mediating the relationship between maltreatment and locus of control: cumulative stress expressed in age or attachment?

Based on the above, this study aimed to investigate the interrelationship between attachment, maltreatment and attributional styles in different age groups. More specifically, the study proposed to identify the locus of control and attachment working models in children who had been sexually abused, i.e., who have suffered sexual contact by the caregiver; physically abused, i.e., who had been beaten by the caregiver, or neglected, i.e., that had not been provided with a minimum standard of a physical (e.g., hygiene, food) or emotional care (according to the definitions of the types of maltreatment by Cicchetti \& Valentino 2006), and to compare them with a control group of similar age. The study also proposed to investigate whether the relationship between maltreatment and locus of control is due more to attachment or cumulative trauma, expressed by the age of the participants.

From the literature discussed in the introduction, the following hypotheses were formulated: (1) cumulative trauma, consisting of being abused over a long period, affects the thinking processes such as styles of attribution and, therefore, in older children a more external locus of control should be observed; (2) cumulative trauma leads to increased insecure type attachment working models, specifically of disorganized type, in older children; (3) age, and therefore multiple trauma, has a greater impact compared to attachment on the locus of control.

\section{Method \\ Participants}

Study participants were 60 children/youths (38 male, $63 \%)$, aged between 5 and 14 years $(M=10.96, \mathrm{SD}=$ $2.9)$, victims of physical abuse $(n=16)$, sexual abuse $(n=14)$ and neglect $(n=30)$ by the parents from an early age, living in several care-homes or who attended the Child Neuropsychiatry Operative Units of different local health authorities in central Italy. With regard to the living arrangements of the children at the time of data collection, 26 children were living with their families of origin, and 34 in external structures, such as care-homes, for a maximum period of two months.

All the families were of high socioeconomic risk. With regard to the education of the parents, $24 \%$ had no type of study, $27 \%$ had elementary education, $28 \%$ had completed "lower middle school" and $21 \%$ had completed "upper middle school". With regard to employment, $64.3 \%$ of parents were working and $33.7 \%$ were unemployed. Finally, the following risk factors associated with maltreatment and/or abuse were found: arrest (9.5\%), illiteracy (7\%), drug dependence (5\%), psychiatric disorders (5\%), and alcoholism (2.5\%).

The group of children victims of maltreatment (MG) was compared with a control group (CG) composed of 100 children (44 male), aged between 7 and 14 years $(M=9.72$, SD $=1.2)$, from medium-low socioeconomic level households and attending different primary schools in Rome, Italy. Regarding the level of parental education, the distribution was: $38 \%$ university degree, $36 \%$ "upper middle school", and $26 \%$ "lower middle school".

The sample was divided into two subgroups according to age group, one composed of children aged between 5 and 9 years (MG, $n=16$, mean age $=7.50, \mathrm{SD}=1.6$; CG, $n=63$, mean age $=7.89, \mathrm{SD}=0.78$ ), and the other composed of youths of pre-teen and adolescent age, i.e., aged 10 to 14 years (MG, $n=44$, mean age $=12.2$ years, $S D=$ 2.08; CG, $n=37$, mean age $=10.0$ years, $\mathrm{SD}=0.6$ ).

\section{Instruments}

For the evaluation of the locus of control, the Italian version by Kirby and Grimley (1989) of the Nowicki-Strickland Locus of Control Scale for Children (Nowicki-Strickland 
Scale - NSS) (1973) was used. This self-administered scale consists of 40 items that refer to beliefs or causes related to events of daily life, for example, to catch a cold, get good grades in school and be scolded for doing something. The answers are dichotomous (yes/no), with a value of $0-1$ being assigned (higher score indicates a more external locus of control). In the case of younger children (5-7 years) the NSS scale was administered by an experimenter who presented the each question of the questionnaire and then wrote down the answers provided. With older children (7-14 years) the scale was selfadministered.

To evaluate the IWM of attachment, the Separation Anxiety Test (SAT) of Klagsbrun and Bowlby (1976, in the version validated in Italy by Attili 2001b) was used. The SAT is a semi-projective test, consisting of a set of six pictures (with a version for boys and another for girls), which represent a child that is about to be left by the parents for a "serious" separation (for the night and parents leave the child at home; for the weekend and the parents leave the child at the house of the aunt; for two weeks and parents leave the child at home) or for a "mild" separation (for the first day of school; in the park, where the parents ask the child to go away, as they want to talk alone; at the time of going to bed when the mother says goodnight and leaves the bedroom). After the presentation of each picture, the experimenter asks four questions: (1) what does the child feel; (2) why does he/she experience this emotion; (3) what will he/she do in the absence of parents; (4) what will the child do or feel when reunited with the parents. The answers related to the emotional reactions are classified into 17 categories (loneliness, sadness, rejection, anger, avoidance, etc.), from which eight classes derived from attachment theory are formed (attachment, lack of self-esteem, hostility, selfconfidence, avoidance, anxiety, anguish, confusion). Through an ordinal scale, a score is given according to the class in which the answers belong. The sum of these scores is used to assign an overall score for each subject, so that it is possible to make a classification, in accordance with the type of attachment, derived from the theory, in terms of secure, ambivalent, avoidant and disorganized.

The test was administered individually by a researcher trained in the application and the coding performed by two specialists in attachment theory, without any prior knowledge regarding the research subject (e.g., types of maltreatment, the locus of control of the subject, etc.). The degree of congruence between the evaluators was $86 \%$ (Cohen's Kappa $=0.82, p<.001$ ).

The same tests (SAT and NSS) that were applied with the MG were also applied individually with the CG. The collected data were entered and tabulated in a spreadsheet and the statistical calculations made using the
SPSS version 21 software,-a figure depicting HOMALS analysis and a table reporting the results of regression analyzes were created.

The study was not submitted to a Research Ethics Committee as this requirement does not exist in Italy. However, it should be mentioned that the study was developed conforming to the recommendations of the Declaration of Helsinki and CNS resolution No. 196/96 and its complements (Brazil 2000).

\section{Statistical analysis}

For the analysis of the data both traditional nonparametric techniques, such as the Kruskal-Wallis test, and correlational analyzes (Pearson and pointbiserial), multiple regression and analysis of variance, as well as multidimensional statistics techniques, such as HOMALS (HOMogeneity analysis by means of Alternating Least Squares), which analyzes the relative homogeneity between categorical variables, were used; the latter procedure allowed the relational structure underlying the set of variables considered to be highlighted (further details in Roazzi et al. 2015).

\section{Results}

\section{Maltreatment, locus of control and cumulative trauma}

Regarding the association between the types of maltreatment and styles of attribution, through the analysis of variance (ANOVA), it was found that the scores of the MG in the scale to measure locus of control (NSS) were significantly higher than those of the control group $\left(M=21.93\right.$ vs $\left.M=18: 56 ; \quad F_{(1,152)}=14.84, p<.001\right)$. Children victims of maltreatment therefore had a higher level of external locus of control.

When the ages of the participants were taken into consideration, it was found, using Pearson's correlation, that in the CG there was a tendency for the older children to present a more internal perception of locus of control $(r=-0.17 ; p=.080)$ - this correlation was marginally significant, while, in the MG a significant presence of an external locus of control was observed with increasing age $(r=0.40 ; p<.002)$.

This trend was observed in the distribution of scores according to the different types of maltreatment: the locus was external with higher scores in the victims of "neglect" $(M=22.3)$, followed by the victims of physical abuse $(M=21.68)$ and then the victims of sexual abuse $(M=21.42)$. These differences, however, were not statistically significant.

When the impact of age was considered, using point-biserial correlations, high scores were found in the NSS scale, with statistically significant results for all the types of maltreatment, i.e., a more external locus of control in the older age groups (dichotomized $10-16$ years $=1$ vs. $5-9$ years $=0)$ : neglect $\left(r_{\mathrm{pb}}=0.55\right.$; 
$p<.002)$; physical abuse $\left(r_{\mathrm{pb}}=0.63 ; p<.010\right)$; sexual abuse $\left(r_{\mathrm{pb}}=0.62 ; p<.017\right)$.

\section{Maltreatment, attachment working models and the incidence of age}

In our study the MG, regardless of the type of maltreatment, presented a prevalence of insecure type internal working models (80\%), which were specifically $30 \%$ avoidant, $27 \%$ disorganized and $23 \%$ ambivalent type. The secure type of attachment was only observed in $20 \%$ of cases. A statistically significant difference was observed in the distribution of attachment between the MG and CG: in the latter, secure attachment was present in $54 \%$ of cases; avoidant in $16 \%$; ambivalent in $27 \%$, and the disorganized pattern of attachment was found in only $3 \%$ of children $\left(X_{(3)}^{2}=31.85, p<.0001\right)$.

When both age groups were considered separately and compared, it was observed that in both the MG and the CG the differences in the distribution of IWM were not significant (the Kruskal-Wallis test: $p>.05$ ). Therefore, the difference between the two age groups for the insecure IWM and the secure IWM, both in the MG and in the CG was not significant.

\section{Maltreatment, attachment and styles of attribution: the interconnection of variables in the overall samples}

With regard to the associations between attachment and attributive styles, it was found that in the CG the secure child participants presented lower scores in the NSS than the insecure one, that is, presented a more internal locus of control. The analysis of variance (ANOVA) showed significant differences among the different attachment models $\left(F_{(3,96)}=5.81, p<.01\right)$. In more detail, the subsequent contrasts made through Duncan's multiple comparisons test indicated that the locus of the secure group $(M=17.13)$ differed significantly $(p<.05)$ from the ambivalent group $(M=20.88)$ the avoidant group $(M=19.43)$ and the disorganized group $(F=20: 26)$. Ambivalent children, however, had a higher and, therefore, more external locus of control, as compared to the avoidant children, although the difference was not significant.

In the MG, however, the NSS scores were all high, regardless of the IWM of the child, so that even the secure subjects presented an external type locus of control, even more external than the other groups (secure $M=23.66$, vs. ambivalent $M=22.27$, vs. avoidant $M=$ 20.67, vs. disorganized $M=21.75$ ), even though the differences between the different IWM were not significant. From the ANOVA, it was noted that the interaction between attachment and maltreatment differed significantly $\left(F_{(3,152)}=4.11, p<.01\right)$, i.e., the children of the MG, both secure and insecure, presented a more external locus of control than the secure and insecure children of the CG. Specifically, Duncan's post hoc test, showed that in the MG the less secure children differed significantly, in the locus of control, from the secure $(p<.001)$, avoidant $(p<0.05)$ and disorganized children $(p<.01)$ of the CG. Furthermore, the MG with ambivalent, avoidant and disorganized IWM presented a more external locus compared to the CG with the corresponding attachments, although the difference was not significant.

\section{The effect of age, or the impact of cumulative trauma}

When considering the differences related to age in the two groups of subjects, given the small number of participants, the IWM were grouped into two categories: secure and insecure. In the CG, the differences, computed through analysis of variance between secure and insecure, regarding the locus of control, were significant in both age groups (age 5/9 secure $M=17.16$ - insecure $M=20.65, F_{(1,62)}=9.49, p<.003$; age $10 / 14$ secure $M=$ 16.36 -insecure $\left.M=19.40 ; F_{(1,35)}=5.04, p<.031\right)$. Thus, the insecure children had a more external locus in both age groups. However, with increasing age, the secure and insecure children both presented a more internal locus, although the difference was not significant.

In the MG, no children were found characterized as secure in the 5-9 years age group, therefore, it was not possible to compare the locus between secure and insecure subjects. In the 10-14 years age group, there was no significant difference between the scores in the NSS of the secure $(M=23.67)$ and insecure children $(M=$ 22.56) $\left(F_{(1,43)}=1.19, p<.281\right)$. With regard to insecurity, however, a significant difference was found ( $p$ $<.003)$ between the $5-9$ years $(M=19.38)$ and $10-14$ years $(M=22.56)$ age groups, i.e., the $M G$ with advanced age presented a more external locus of control.

\section{Predictors of locus of control Age and attachment}

Next, through a series of multiple regressions, an attempt was made to identify the predictor for the locus of control in both the MG and the CG. Table 1 shows two types of multiple regression analysis: stepwise and fixed step. In the first stepwise analysis, both attachment and age, were considered as the independent variables. The results revealed that, while in the CG the predictor of the locus of control was attachment, explaining $37 \%$ of the variance, in the MG the predictor was age, explaining $15.5 \%$ of the variance.

Next, to identify the specific weight of the two variables, i.e., one in relation to the other, fixed step type regressions were performed controlling the order. In the CG, while attachment explained the locus of control well when it was entered as the first step $(13.7 \%)$, and when entered as the second step (12.4\%), age, did not exhibit a significant weight for explaining the locus of control. 
Table 1 Stepwise and fixed step multiple regressions considering as dependent variable Locus of Control

\begin{tabular}{|c|c|c|c|c|c|c|c|c|}
\hline IV/Steps & $\mathrm{R}$ & $R^{2}$ & $r^{\text {Pearson }}$ & $R^{2 \text { Change }}$ & $F^{\text {Change }}$ & df1 & $\mathrm{df} 2$ & $p$ \\
\hline IV: Attach. \& Age & & & & Stepwise & & & & \\
\hline \multicolumn{9}{|l|}{ Control } \\
\hline Secure Attachment & .370 & .137 & -.370 & .370 & 15.562 & 1 & 98 & .000 \\
\hline \multicolumn{9}{|l|}{ Maltreated } \\
\hline \multirow[t]{2}{*}{ Age } & .394 & .155 & .394 & .155 & 10.679 & 1 & 58 & .002 \\
\hline & & & & Fixed Ster & & & & \\
\hline \multicolumn{9}{|l|}{ Control } \\
\hline $1^{\text {th }}$ Sec. Attachment & .370 & .137 & -.370 & .137 & 15.562 & 1 & 98 & .001 \\
\hline $2^{\text {nd }}$ Age & .388 & .150 & -.163 & .013 & 1.526 & 1 & 97 & .220 \\
\hline \multicolumn{9}{|l|}{ Maltreated } \\
\hline $1^{\text {th }}$ Sec. Attachment & .253 & .064 & .253 & .064 & 3.956 & 1 & 58 & .051 \\
\hline $2^{\text {nd }}$ Age & .450 & .203 & .394 & .139 & 9.910 & 1 & 57 & .003 \\
\hline \multicolumn{9}{|l|}{ Control } \\
\hline $1^{\text {th }}$ Age & .163 & .027 & -.163 & .027 & 2.686 & 1 & 98 & .104 \\
\hline $2^{\text {nd }}$ Sec. Attachment & .388 & .150 & -.370 & .124 & 14.126 & 1 & 97 & .000 \\
\hline \multicolumn{9}{|l|}{ Maltreated } \\
\hline $1^{\text {th }}$ Age & .394 & .155 & .394 & .155 & 10.679 & 1 & 58 & .002 \\
\hline $2^{\text {nd }}$ Sec. Attachment & .450 & .203 & .253 & .047 & 3.361 & 1 & 57 & .072 \\
\hline IV: Attach. \& Malt. & & & & Stepwise & & & & \\
\hline \multicolumn{9}{|l|}{$5-9$ years } \\
\hline Secure Attachment & .319 & .102 & -.319 & .102 & 8.717 & 1 & 77 & .004 \\
\hline \multicolumn{9}{|l|}{ 10-14 years } \\
\hline \multirow[t]{2}{*}{ Maltreated } & .591 & .350 & .591 & .350 & 42.464 & 1 & 79 & .001 \\
\hline & & & & Fixed Step & & & & \\
\hline \multicolumn{9}{|l|}{$5-9$ years } \\
\hline $1^{\text {th }}$ Maltreated & .025 & .001 & .025 & .001 & .049 & 1 & 77 & .825 \\
\hline $2^{\text {nd }}$ Sec. Attachment & .340 & .116 & -.319 & .115 & 9.880 & 1 & 76 & .002 \\
\hline \multicolumn{9}{|l|}{ 10-14 years } \\
\hline $1^{\text {th }}$ Maltreated & .591 & .350 & .591 & .350 & 42.464 & 1 & 79 & .001 \\
\hline $2^{\text {nd }}$ Sec. Attachment & .600 & .360 & -.230 & .011 & 1.318 & 1 & 78 & .255 \\
\hline \multicolumn{9}{|l|}{$5-9$ years } \\
\hline $1^{\text {th }}$ Sec. Attachment & .319 & .102 & -.319 & .102 & 8.717 & 1 & 77 & .004 \\
\hline $2^{\text {nd }}$ Maltreated & .340 & .116 & .025 & .014 & 1.196 & 1 & 76 & .278 \\
\hline \multicolumn{9}{|l|}{ 10-14 years } \\
\hline $1^{\text {th }}$ Sec. Attachment & .230 & .053 & -.230 & .053 & 4.376 & 1 & 79 & .056 \\
\hline $2^{\text {nd }}$ Maltreated & .600 & .360 & .591 & .307 & 33.668 & 1 & 78 & .001 \\
\hline
\end{tabular}

Secure Attachment $=0$ Insecure, 1 Secure $\left(\right.$ Sec.); $1^{\text {th }}=$ First Step; $2^{\text {nd }}=$ Second Step Note 1: In bold statistically significant results. Note $2:$ IV = Independent Variable

In the MG, in contrast, age explained the locus of control, both when inserted as a first step (15.5\%), and when included as a second step (13.9\%), while attachment did not present a significant weight in the explaining the locus of control. This indicates the different weight, in both groups, that these two variables, 
attachment and age, play in relation to the locus of control.

\section{Attachment and maltreatment}

Subsequently, the weight of the attachment and maltreatment was verified in both age groups. For this, further regression analyses were performed considering the entire sample of 100 control subjects and 60 maltreatment victims. As shown in Table 1, while in the 5-9 years group (CG $n=63+$ MG $n=16$ ) the attachment variable explained more the locus of control $(10.2 \%, r=-.319)$, in the 10-14 years age group (CG $n=37+$ MG $n=44$ ) the maltreatment variable significantly explained the locus of control dependent variable (35\%,r=.59). This means that, in the children 5-9 years of age, a significant association was detected between secure attachment and internal locus of control, clearly being the result of a greater presence of the control group in this age group, with the majority presenting a secure attachment. It was also observed that in the youths of 10-14 years of age, there was a significant association between maltreatment and external locus of control.

Finally, to detect the specific weight of the two variables, subsequent fixed step regressions were performed. In the 5-9 years age group, only attachment explained the locus of control in both the first step $(10.2 \%, r=-.319)$, and the second step $(11.5 \%, R=$ -.319). In the 10-14 years age group, in contrast, only the maltreatment variable explained the locus of control, in both the first step (35\%,r=0.59), and the second step $(30.7 \%, R=0.59)$. This seems to indicate that the variables attachment and maltreatment have a different weight in both age groups considered-as in the children of 5-9 years an association between secure attachment and internal locus of control was observed and in the children of 10-14 years an association between maltreatment and external locus of control was observed, as stated above.

The interaction between the locus of control, attachment and abuse: a multidimensional analysis

To verify the interaction between locus and attachment in the CG and MG, separated by age, multi-dimensional analysis was performed, using the HOMALS statistical procedure. This HOMALS analysis showed a clear differentiation between the children of the CG and those of the MG (right and left region, respectively, of the projection), which corresponded exactly to the location of the locus of control-the internal locus on the right and the external locus on the left. A strong association between the internal locus and the CG and the external locus and the MG was observed. Within the right area, where the four subgroups of control are located, it was noted that in the extreme right, the two control groups were of secure youths. Moving to the left, the other two insecure attachment subgroups of control were located in the middle region of the projection. The three subgroups of the MG were located in the left region. The two insecure groups were located very close to the external locus, while the third MG group, secure subjects, was located at a position below the other two insecure groups. From this arrangement, it is possible to observe the location of the four insecure subgroups (MG and CG) in the upper left region.

This arrangement of the subgroups according to group type (CG vs. MG) and the type of attachment (secure vs. insecure) indicates that these two dimensions are distributed in an axial structure, revealing the existence of a logic of location as a function of the locus (Internal vs. External). In fact, the two groups of control for the respective age groups had the highest association coefficients (Jaccard) with internal locus of control, both with Jaccard values of 0.63 . Regarding the external locus, the two highest association coefficients were found for the maltreatment group with insecure attachment in both age groups, these being 0.51 for the 5-9 years age group and 0.56 for the 10-14 years age group (Fig. 1).

\section{Discussion}

The study results show that in the MG there was a significant prevalence of harmful sociocognitive skills, such as the use of attributive styles that are based on reporting causes of events as external, in line with what has been observed in other studies (e.g., Barahal et al. 1981). In other words, the children/youths that had been victims of maltreatment showed little confidence in the

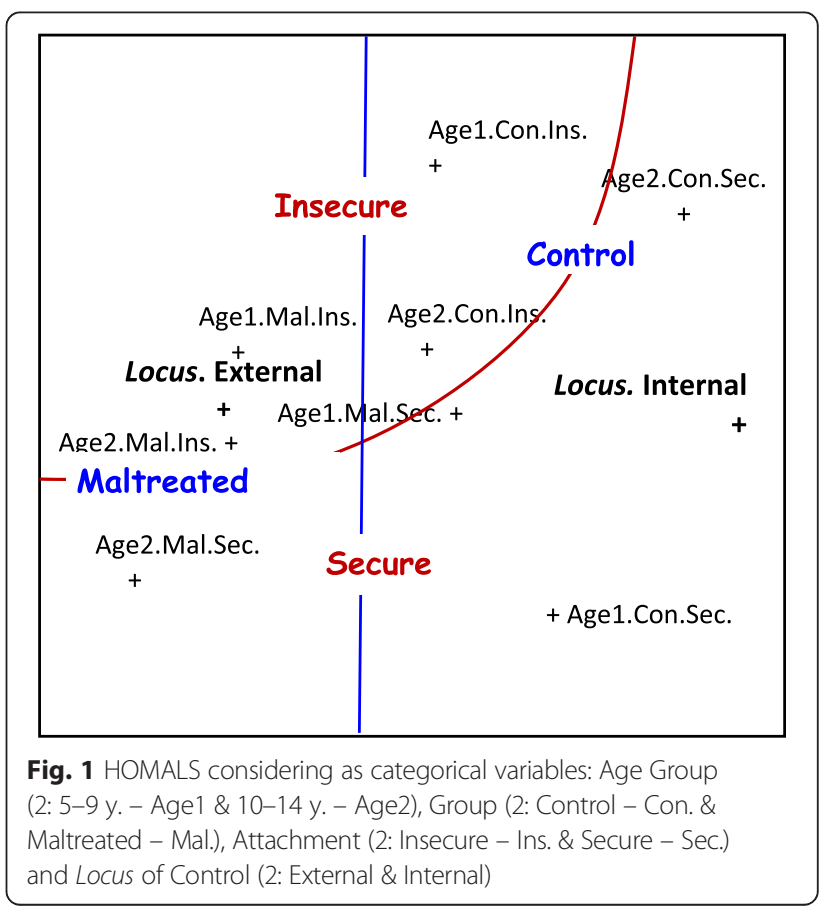


possibility that they could have an impact on their own experiences. This altered perception of the causes of events can be considered a realistic and defensive adaptation to the environmental circumstances, however, can also be seen as precursor for the passivity and sense of helplessness, powerlessness and abandonment that occur in adults who were abused in childhood (Cole \& Putnam 1992; Drapeau \& Perry 2004), and for the internalizing symptoms that occur in people who were victims of maltreatment in childhood (Bolger \& Patterson 2001). The presence of fewer depressive symptoms was found in women of low-income, who had been abused in childhood and that, in some way, had been able to develop an internal locus of control, than in women that had an external locus of control (Banyard 1999). In other words, an internal locus of control can act as a protective factor against the possible emergence of internalizing symptoms, however, the experiences of maltreatment make this extremely difficult to achieve.

Confirming the first hypothesis, the study results also indicate that the older children, who began to suffer maltreatment at an early age and, therefore, presented a cumulative trauma, had a more external locus of control compared to the younger children, suggesting the hypothesis that the maltreatment that starts at an early age exacerbates the risk factor constituted by the perception of an external locus.

Some studies have demonstrated an interaction between locus of control and cumulative stress: adolescent girls that had been victims of maltreatment from an early age tended to have a less internal locus and presented a higher level of depressive symptoms than those in which the maltreatment had started at the end of adolescence (Moran \& Eckenrode 1992). In other words, maltreatment that starts early could prevent the development of a sense of autonomy and competence, based on the feeling of being in control of events, with this feeling appearing, in the majority of studies, to be related to the experiences of early childhood (e.g., Cicchetti et al. 1991; Creasey \& Jarvis 1994; Sroufe 1996).

The children who were victims of maltreatment also presented insecure attachment in $80 \%$ of cases, with a significantly different distribution observed in the control group: only $20 \%$ of the MG appeared secure, compared to $54 \%$ of the CG; $27 \%$ of the MG were disorganized, compared to $3 \%$ of CG; and $30 \%$ were avoidant, compared to $16 \%$ of the CG. From the results it can be seen that, therefore, a similar attachment was present in children victims of maltreatment, this being both disorganized and avoidant. This distribution seems to remain constant with age, which does not confirm the second hypothesis. This unexpected result can be interpreted based on the idea that the attachment working models are formed at an early stage and are stable throughout life, so that it is the early childhood experiences that influence the mental structures, in line with the conclusions of the recent meta-analysis of Cassibba, Sette, Bakermans-Kranenburg and van Ijzendoorn (2013) on the distribution of attachment in typical and atypical samples. The presence in the MG of avoidant mental models, as opposed to just disorganized, can be interpreted in the light of strong defense mechanisms that could be triggered in these children and lead to withdrawal and denying themselves access to the emotions, rather than being confused by them, as usually occurs in the disorganized pattern. It was not by chance that a study by Finzi, Har-Even, Shnit and Weizman (2002) observed, in the majority of abused children, a high percentage of avoidant patterns, accompanied by high levels of depression and suicidal symptoms.

The most interesting result of the data found in the present study, however, concerns the relationship between attachment and cumulative trauma, due to exposure to abuse for a long period of time, showing the emergence of the attributional style. While in the CG attachment was the predictor for the locus of control in both age groups considered, in the MG the accumulation of stress due to maltreatment suffered over a long period, and therefore age, more accurately predicted an attributional style based on reporting causes of events as external, supporting the hypothesis proposed. This result is confirmed, both in the analysis-considering the total sample $(C G+M G)$, in order to highlight the predictive value of the attachment variable versus the maltreatment variable regarding the locus of control in both age groups-as well as in the analysis performed using the HOMALS technique. In the latter analysis, while in the group of younger children attachment predicted the locus of control, in the group of older children maltreatment was the predictor variable. In addition, the locus was more internal in the CG in both age groups, in both the secure and insecure subjects, in line with what was found by La Montagne (LaMontagne 1984, 1987) and Nowicki and Duke (1983), while this was external in the MG, regardless of the type of attachment, and even more external in the older subjects.

\section{Conclusion}

These results and analysis are unique in the literature and make it possible to argue more in favor of the hypothesis that the greater the age, the more victims of maltreatment are likely to experience serious internalizing problems, such as anxiety (e.g., as a result of the inability to give meaning to their own experiences), rather than this being a result of attachment working models of the avoidant or disorganized type, which also have an impact on their mental health. 
When an individual has a perception of adequate control over events, this can reduce their perception of being threatened (Lazarus \& Folkman 1984). Furthermore, it has been found in non-clinical samples, that older children experience a lower state of anxiety when faced with a stressful situation compared to younger children, as a result of the emergence, with age, of a greater perception of controlling events (Li \& Chung 2009), which is associated with the data of the present study, in which a more internal locus of control in older subjects emerged in the CG, but not in the MG.

Our results present several implications with regard to intervention. Our data show how maltreatment, especially when linked with the cumulative trauma, affects the development of self, perceived self-efficacy and all the cognitive skills that form the basis of social skills. As stated above, abuse that starts at an early age prevents the development of a sense of autonomy and competence, based on the feeling of being in control of events. In the studies of Cicchetti, Beeghly, Carlson, Coster, Gersten, Rieder and Toth (1991), Creasey and Jarvis (1994) and Sroufe (1996) it was observed that the feeling of having control over one's life is closely related with the experience of early childhood.

Children victims of maltreatment investigated in this study, due to severely distorted experiences, developed mental models of self and other features in negative terms, which are accompanied by an attribution style characterized by the belief that the causes of events are mainly external and out of their control. In other words, there is a coherent style of attribution with a self-representation based on a sense of limited personal competence in the children of the MG, but not in the children of the CG. The psychotherapeutic and psychoeducational intervention could focus on a restructuring of a sense of self in terms of greater personal efficiency through experiences of a relationship characterized by feeling emotional support, and through conversations and exercises dedicated to the elicitation of a more enhanced understanding of how events can be solved in the best way, making the person feel part of the process of structuring the events.

\section{Limitation of the study}

Several limitations can be detected in this study. Above all, the low number of participants stands out, so that these results, even though partly in accordance with the literature in the area, must be confirmed by further studies, preferably opting for non-parametric analysis. The unequal distribution of the IWM within each group investigated also needs to be considered. For example, in the CG, despite the reasonable number of participants $(N=100)$, only three children with disorganized attachment were detected. Another limitation concerns the incomplete overlap of the two age groups of individuals in the two groups considered, although this difference was offset by the fact that in $53 \%$ of cases, the age was the same. It would therefore be desirable to replicate this study comparing totally homogeneous groups of subjects. A final limitation stems from the fact that, based on the study data, it was not possible to decide whether it was the maltreatment per se that affected the security of the attachment and the locus of control or whether the socioeconomic characteristics (high risk) that characterized the sample investigated were responsible for both dimensions (for further details see Cyr et al. 2010). It is likely, however, that, in the sample of the present study, an accumulation of both relational and socioeconomic types of risks had a devastating impact on the cognitive dimensions, such as attribution styles and attachment working models. Another limitation was to consider that the cumulative trauma can be deduced from age. This is a presumption, therefore it is suggested that future studies adopt forms of verification of the level of severity/intensity of the maltreatment suffered by the children of the study sample.

Finally, additional investigations, in order to control the limitations outlined above, are necessary to enable further advances in the area, which are important for establishing clinical approaches that help to propose effective forms of treatments for children and youths that have been victims of maltreatment.

\section{Competing interests}

The authors declare that they have no competing interests.

\section{Authors' contributions}

All authors collected and analysed data, reviewed the literature, and participated in writing the manuscript. All authors read and approved the final manuscript.

\section{Author details}

${ }^{1}$ Department of Psychology, Graduate Program in Cognitive Psychology, Federal University of Pernambuco, Recife, Brazil. ${ }^{2}$ Department of Social and Economical Sciences, Sapienza University of Rome, Rome, Italy.

Received: 9 March 2016 Accepted: 7 April 2016

Published online: 14 April 2016

\footnotetext{
References

Attili G. Maltrattamento infantile ed attaccamento: I'organizzazione filogenetica del pattern disorganizzato. Maltrattamento e Abuso all'Infanzia. 2001a;3(3):49-60.

Attili G. Ansia da separazione e misura dell'attaccamento normale e patologico. Versione modificata e adattamento italiano del Separation Anxiety Test (SAT). Milano: Unicopli; 2001 b.

Attili G. Normalità, patologia, terapia. Milano: Raffaello Cortina Editore; 2007. Attaccamento e costruzione evoluzionistica della mente.

Bacon H, Richardson S. Attachment theory and child abuse: An overview of the literature for practitioners. Child Abuse Rev. 2001;10(6):377-97. doi:10.1002/car.718. Banyard VL. Childhood maltreatment and the mental health of low-income women. Am J Orthopsychiatry. 1999;69:161-71.

Barahal RM, Waterman J, Martin HP. The social cognitive development of abused children. J Consult Clin Psychol. 1981;49(4):508-16.

Beaudoina G, Hébert M, Bernier A. Contribution of attachment security to the prediction of internalizing and externalizing behavior problems in
} 
preschoolers victims of sexual abuse. European Review of Applied Psychology. 2013;63:147-57.

Beumariu LE, Kerns KA. Parent-child attachment and internalizing symptoms in childhood and adolescence: A review of empirical findings and future directions. Dev Psychopathol. 2010;22(1):177-203.

Bifulco A, Moran PM, Baines R, Bunn A, Stanford K. Exploring psychological abuse in childhood: II Association with other abuse and adult clinical depression. Bulletin of Menninger Clinic. 2002;66:241-58.

Bolger KE, Patterson CJ. Pathways from child maltreatment to internalizing problems: Perceptions of control as mediators and moderators. Dev Psychopathol. 2001;13:913-40.

Brasil. Ministério da Saúde. Resolução CNS 196/96. It sets the standards for research involving human subjects. Brasília: Conselho Nacional de Saúde. Comissão Nacional de Ética em Pesquisa; 2000.

Camisasca E, Di Blasio P, Mirangoli S. La disorganizzazione dell'attaccamento spiega i sintomi post-traumatici nei bambini vittime di violenza? Paper presented to the XXVI Congresso AIP 2013. Milano: Psicologia dello Sviluppo e dell'Educazione; 2013.

Cantón J, Cortés MR. El apego del niño a sus cuidadores. Madrid, Spain: Alianza; 2008.

Canton-Cortes D, Cortes MR, Canton J. Child Sexual Abuse, Attachment Style, and Depression: The Role of the Characteristics of Abuse. J Interpers Violence. 2015;30(3):340-59. doi:10.1177\%2F0886260514535101.

Carlson EA. A prospective longitudinal study of attachment disorganization/ disorientation. Child Dev. 1998;69(4):1107-28.

Carlson V, Cicchetti D, Barnett D, Braunwald K. Disorganized/disoriented attachment relationships in maltreated infants. Dev Psychol. 1989;25:525-31. doi:10.1037/0012-1649.25.4.525.

Cassibba R, Sette G, Bakermans-Kranenburg MJ, Van IJzendoorn MH. Attachment the Italian way: In search of specific patterns of infant and adult attachments in Italian typical and atypical samples. Eur Psychol. 2013;18(1):47-58.

Cicchetti D, Beeghly M, Carlson V, Coster W, Gersten M, Rieder C, Toth S. Development and psychopathology: Lessons from the study of mal treated children. In: Keating DP, editor. The Jean Piaget Symposium Series: Constructivist perspectives on developmental psychopathology and atypical development. Hillsdale, NJ: Erlbaum; 1991. p. 69-102.

Cicchetti D, Rogosch FA, Toth SL. Fostering secure attachment in infants in maltreating families through prevention interventions. Dev Psychopathol. 2006:18:623-49.

Cicchetti D, Valentino K. An Ecological-Transactional Perspective on Child Maltreatment: Failure of the Average Expectable Environment and its Influence on Child Development. In: Cicchetti D, Cohen D, editors. Developmental psychopathology. Hoboken, NJ: John Wiley; 2006.

Cole PM, Putnam FW. Effect of incest on self and social functioning: A developmental psychopathology perspective. J Consult Clin Psychol. 1992;60:174-84.

Creasey GL, Jarvis PA. Relationships between parenting stress and developmental functioning among 2-year-olds. Infant Behavior and Development. 1994;17:423-9.

Crittenden PM. Maltreated infants: Vulnerability and resilience. J Child Psychol Psychiatry. 1985;26:85-96.

Crittenden PM. Children's strategies for coping with adverse home environments: An interpretation using attachment theory. Child Abuse Negl. 1992;16:329-43.

Crittenden PM, Ainsworth MDS. Child Maltreatment and Attachment Theory. In: Cicchetti C, Carlson V, editors. Handbook of Child Maltreatment. Cambridge: Cambridge University Press; 1989.

Cyr C, Euser EM, Bakermans-Kronenburg MJ, van ljzendoorn MH. Attachment security and disorganization in maltreating and high-risk families: A series of meta-analyses. Dev Psychopathol. 2010;22:87-108.

Dan O, Sagi-Schwartz A, Bar-haim Y, Eshel Y. Effects of early relationships on children's perceived control: A longitudinal study. Int J Behav Dev. 2011;35(5):449-56.

De Wolff MS, van IJzendoorn MH. Sensitivity and attachment: A meta-analysis on parental antecedents of infant attachment. Child Dev. 1997;68:571-91.

Di Pentima L, Toni A. Stili attribuzionali e attaccamento in età infantile e in età adulta. Età Evolutiva. 2010;95:42-58.

Drapeau M, Perry JC. Childhood trauma and adult interpersonal functioning: A study using the Core Conflictual Relationship Theme Method (CCRT). Child Abuse Negl. 2004;28:1049-66.

Ellis RH, Milner JS. Child abuse and locus of control. Psychol Rep. 1981;48:507-10.

Finzi R, Har-Even D, Shnit D, Weizman A. Psychosocial characterization of physically abused children from low socioeconomic households in comparison to neglected and nonmaltreated children. J Child Fam Stud. 2002;11(4):441-53.
Fonagy P. Attachment and borderline personality disorder. Journal of the American Psychoanalytical Association. 2000:48:1129-47.

Gamble SA, Roberts JE. Adolescents' perceptions of primary caregivers and cognitive style: The roles of attachment security and gender. Cogn Ther Res. 2005;29:123-41.

Hexel M. Alexithymia and attachment style in relation to locus of control. Personal Individ Differ. 2003;35:1261-70.

Hubbs-Tait L, Hughes K, Culp A, Osofsky J, Hann D, Eberhart-Wright A, et al. Children of adolescent mothers: attachment representation, maternal depression and later behavioural problems. Am J Orthopsychiatry. 1996;66:416-26.

Kim K, Trickett PK, Putnam FW. Attachment representations and anxiety: Differential relationships among mothers of sexually abused and comparison girls. J Interpers Violence. 2011;26:498-521.

Kirby E, Grimley L. Disturbi dell'attenzione e iperattività. Trento: Erickson; 1989.

Klagsbrun M, Bowlby J. Responses to separation from parents: A clinical test for young children. Projective Psychology. 1976;21:7-27.

LaMontagne LL. Children's locus of control beliefs as predictors of preoperative coping behavior. Nurs Res. 1984;33(2):76-85.

LaMontagne LL. Children's preoperative coping: Replication and extension. Nurs Res. 1987;36(3):163-7.

Lazarus RS, Folkman S. Stress, appraisal, and coping. New York: Springer; 1984

Lecompte V, Moss E. Disorganized and controlling patterns of attachment, role reversal, and caregiving helplessness: links to adolescents' externalizing problems. Am J Orthopsychiatry. 2014;84(5):581-9. doi:10.1037/ort0000017.

Lefcourt HM. Locus of control: Current trends in theory and research. 2nd ed. Hillsdale, NJ: Erlbaum; 1982.

Li HCW, Chung OKJ. The relationship between children's locus of control and their anticipatory anxiety. Public Health Nurs. 2009;26(2):153-60.

Lyons-Ruth K, Bronfman E, Parsons E. Maternal frightened, frightening, or atypical behavior and disorganized infant attachment patterns. Monogr Soc Res Child Dev. 1999;258(64):67-96.

Lyons-Ruth K, Jacobvitz D. Attachment Disorganization: Unresolved Loss, Relational Violence, and Lapses in Behavioral and Attentional Strategies. In: Cassidy J, Shaver PR, editors. Handbook of attachment: Theory, research, and clinical applications (1st ed., pp. 520-554). New York: Guilford Press; 1999.

Lyons-Ruth K, Jacobvitz D. Attachment disorganization: Genetic factors, parenting contexts, and developmental transformation from infancy to adulthood. In: Cassidy J, Shaver PR, editors. Handbook of attachment: Theory, research, and clinical applications. 2nd ed. New York: Guilford Press; 2008. p. 666-97.

Main M, Solomon J. Discovery of an insecure disoriented attachment pattern: procedures, findings and implications for the classification of behavior. In: Brazelton T, Youngman M, editors. Affective Development in Infancy. Norwood, NJ: Ablex; 1986. ISBN 0-89391-345-6.

Main M, Solomon J. Procedures for Identifying Infants as Disorganized/disoriented During the Ainsworth Strange Situation. In: Greenberg MT, Cicchetti D, Cummings EM, editors. Attachment in the preschool years: Theory, research, and intervention. Chicago: University of Chicago Press; 1990. p. 121-60.

McElheran M, Briscoe-Smith A, Khaylis A, Westrup D, Hayward C, Gore-Felton C. A conceptual model of post-traumatic growth among children and adolescents in the aftermath of sexual abuse. Counseling Psychology Quarterly. 2012;25:73-82.

Mickelson KD, Kessler RC, Shaver PR. Adult attachment in a nationally representative sample. J Pers Soc Psychol. 1997;73:1092-106.

Miner MH, Swinburne Romine R, Robinson BBE, Berg D, Knight RA. Anxious Attachment, Social Isolation, and Indicators of Sex Drive and Compulsivity: Predictors of Child Sexual Abuse Perpetration in Adolescent Males? Sexual Abuse: A Journal of Research and Treatment. 2014;26:610-28. doi:10.1177/ 1079063214547585.

Moran PB, Eckenrode J. Protective personality characteristics among adolescent victims of maltreatment. Child Abuse Negl. 1992;16:743-54.

Moss E, Dubois-Comtois K, Cyr C, St-Laurent D, Tarabulsy GM, Bernier A, Larin S. Can caregiving behavior of maltreating mothers be changed? In C, George \& J. Solomon (Chairs). Boston, MA: Symposium presented at the biennial meeting of the Society for Research in Child Development; 2007.

Neufeld Bailey H, Moran G, Pederson DR. Childhood maltreatment, complex trauma symptoms, and unresolved attachment in an at-risk sample of adolescent mothers. Attach Hum Dev. 2007;9(2):139-61.

Nowicki S, Duke MP. The Nowicki-Strickland life-span locus of control scales: Construct validity. Research with the locus of control construct. 1983;2(1):9-51.

Nowicki S, Strickland BR. A locus of control scale for children. J Consult Clin Psychol. 1973;40:148-54. 
O'Connor E, Bureau J-F, McCartney K, Lyons-Ruth K. Risks and Outcomes Associated with Disorganized/Controlling Patterns of Attachment at Age Three in the NICHD Study of Early Child Care and Youth Development. Infant Mental Health. 2011;32(4):450-72. doi:10.1002/imhj.20305.

Phares EJ. Locus of control in personality. Morristown, N.J: General Learning Press; 1976.

Roazzi A, do Nascimento AM, da S Gusmão EE. O Significado do Apego e da Interação Social no Desenvolvimento do Self, Autoconsciência e Teoria da Mente. In: Taveira R, da S Gusmão EE, editors. Psicologia: Conceitos, Técnicas e Pesquisas Vol I. (pp. 109-144). Curitiba, PR: CRV; 2013.

Roazzi A, Souza BC, Bilsky W. Facet Theory: Searching for structure in Complex Social, Cultural and Psychological Phenomena. Recife/PE: Editora Universitária - UFPE; 2015.

Rotter JB. Generalized expectancies for internal versus external control of reinforcement. Psychological Monograph. 1966:80:1-28.

Serrano AC, Zuelzer MB, Howe DD, Reposa RE. Ecology of abusive and nonabusive families. J Am Acad Child Psychiatry. 1979;18:167-75.

Sroufe LA. Emotional development: The organization of emotional life in the early years. New York: Cambridge University Press; 1996.

Unger JAM. The relationship between child abuse and adult attachment styles. Winnipeg, Canada: University of Manitoba; 2011.

van der Kolk BA. Childhood abuse and neglect and loss of self-regulation. Bull Menninger Clin. 1994;58(2):145-68.

Webster L, Kisst Hackett R, Joubert D. Association of unresolved attachment status and cognitive processes in maltreated adolescents. Child Abuse Rev. 2009;18(1):6-23.

\section{Submit your manuscript to a SpringerOpen ${ }^{\odot}$ journal and benefit from:}

- Convenient online submission

- Rigorous peer review

- Immediate publication on acceptance

- Open access: articles freely available online

- High visibility within the field

- Retaining the copyright to your article 